\section{Within-trial contrast: When you see it and when you don't}

\author{
Thomas R. Zentall \\ University of Kentucky, Lexington, Kentucky
}

Within-trial contrast occurs when a discriminative stimulus that is preceded by a relatively aversive event is preferred over another that is preceded by a less aversive event. Recent failures to replicate (Arantes \& Grace, 2008; Vasconcelos, Urcuioli, \& Lionello-DeNolf, 2007) may allow us to identify factors that may be responsible. In the case of Vasconcelos et al., it is likely that insufficient training was provided (often 35-65 sessions are required). In the case of Arantes and Grace (Experiment 2), these pigeons had been involved in prior experiments involving lean schedules of reinforcement, and we find that prior experience with lean (relatively aversive) schedules appears to reduce the presumed aversiveness of the many-peck requirement, thus obviating the contrast effect. Finally, in the case of Vasconcelos and Urcuioli (2008), although the contrast effect with a simultaneous discrimination was not reliable, it was not reliably smaller than with a successive discrimination that did show a reliable effect, and the contrast effect was also similar in magnitude to a reliable effect reported by Kacelnik and Marsh (2002). Thus, although there have been several failures to replicate the original effects reported by Clement, Feltus, Kaiser, and Zentall (2000), insufficient training, prior history with lean schedules of reinforcement, and low statistical power may have been responsible for those failures.

When a phenomenon has been reported in the literature and has been verified under a number of different conditions in more than one lab, it is generally viewed as a reliable phenomenon. But the within-trial contrast effect, first reported by Clement, Feltus, Kaiser, and Zentall (2000) as a "work ethic" in pigeons, has recently been found to be not as reliable a phenomenon as was originally thought. Two articles in the present issue of this journal (Arantes \& Grace, 2008; Vasconcelos \& Urcuioli, 2008), as well as a recent article published elsewhere (Vasconcelos, Urcuioli, \& Lionello-DeNolf, 2007), have questioned the reliability of the effect as well as the conditions under which the phenomenon can be found.

The failure to reproduce a well-studied phenomenon can facilitate the development of a unified theory by identifying the conditions under which the phenomenon can and cannot be found. The overtraining reversal effect (ORE) may be such a phenomenon. When animals are overtrained on a simple discrimination, they are often able to reverse that discrimination faster than when they are trained to a criterion (but not overtrained). Mackintosh (1965) noted that most of the reported failures to find the ORE occurred when the discrimination was quite easy_-for example, when it involved a spatial (left/right) discrimination. Mackintosh reasoned that the ORE likely resulted from an increase in attention (to the dimension defined by the discrimination) during overtraining, but if the relevant dimension was already well-attended-to prior to overtraining, as would likely be the case with a spatial discrimination, the ORE would fail to occur. Thus, ideally, specification of the conditions under which the within-trial contrast effect does not occur should lead to a better understanding of the mechanism responsible for its occurrence.

Before attempting to account for the reported failures to replicate the within-trial contrast effect, it should be noted that a failure to replicate an effect does not always imply that the original effect was a Type I error - the finding of an effect when none exists (i.e., a sampling error). Some failures to replicate are Type II errors - the failure to observe an effect when one does exist. But that said, it is functionally more appropriate to attempt to account for such failures than to attribute them to sampling error.

The failure to replicate that is easiest to deal with was reported by Vasconcelos et al. (2007). This was an attempt to replicate our original finding (Clement et al., 2000). Pigeons were trained on two simultaneous discriminations - to choose red $\left(\mathrm{S}^{+}\right)$, for example, in the presence of yellow $\left(\mathrm{S}^{-}\right)$and to choose green $\left(\mathrm{S}^{+}\right)$in the presence of blue $\left(\mathrm{S}^{-}\right)$. To obtain the simultaneous discriminations on the side keys, the pigeons were required to peck the center key. On half of the trials, a single peck was sufficient to produce the simultaneous discriminationwhen, for example, it was the red/yellow discrimination. On the remaining trials, 20 pecks were required to produce the simultaneous discrimination-when it was the green/blue discrimination. On probe trials, the pigeon was given a choice between the two positive stimuli (red and green). Overall, we found that the pigeons were twice as likely to choose the positive hue that during training had required greater effort to obtain.

This effect was very similar to the justification-ofeffort effect (cognitive dissonance) reported by Aronson and Mills (1959), in which students who had to undergo a severe initiation to join a group valued the group more than others for whom the initiation was mild. However, we proposed a contrast model to account for this finding, and

T. R.Zentall, zentall@uky.edu 
we predicted that other relatively aversive events would produce a similar preference for the positive discriminative stimulus that followed. In support of this prediction, DiGian, Friedrich, and Zentall (2004) found that pigeons preferred the positive discriminative stimulus that followed a delay over one that on other trials did not follow a delay. Similarly, Friedrich, Clement, and Zentall (2005) found that pigeons preferred a positive discriminative stimulus that followed the absence of food over one that on other trials followed the presence of food.

Because in each case the simultaneous discriminations were quite easy to acquire and because we had no measure of the association between the relatively aversive event and the discriminative stimuli that followed, we trained pigeons for 20 ninety-six-trial sessions beyond acquisition of a simultaneous discrimination. Only in a later experiment, when we monitored the development of the association between the relatively aversive event and the discriminative stimuli that followed by using probe trials during overtraining, did we discover that 20 overtraining sessions was often not sufficient for the development of this within-trial contrast effect (see Friedrich \& Zentall, 2004; Singer, Berry, \& Zentall, 2007; Singer \& Zentall, 2007). For example, Singer et al. found that a reliable preference for the $\mathrm{S}^{+}$stimulus that followed the lesspreferred prior event did not emerge until the pigeons had had 30 sessions of overtraining. In a similar experiment, part of a larger study, a reliable preference required more than 30 overtraining sessions to emerge, and in a second experiment a reliable preference emerged only after 40 overtraining sessions (Singer \& Zentall, 2007). And previously, using a somewhat different design involving a shift in the preference for a feeder location that required greater effort to obtain, Friedrich and Zentall found that a reliable preference did not emerge until the pigeons had experienced 60 sessions of overtraining. It appears that the association between the prior event and the simultaneous discrimination develops rather slowly and that association is critical for the development of the reported contrast effect. Thus, 20 sessions of overtraining is likely to be the lower limit for finding the effect, and often additional training is required.

A more difficult result to account for is that reported by Arantes and Grace (2008). In their first experiment, pigeons were trained to criterion and then tested. Although a preference for the $\mathrm{S}^{+}$that followed the greater effort was not found, the negative result could be attributed to the minimal amount of training provided.

In their second experiment, the procedure involved nine blocks of 3 training sessions followed by a testing session. Thus, a total of 27 training sessions had 9 testing sessions interspersed. Again, it is possible that the amount of training was not enough to sufficiently strengthen the association between the pecking requirement and the discriminative stimuli that followed. However, a subgroup of 4 pigeons was given more than twice the number of training sessions, and although they did show a preference for the $\mathrm{S}^{+}$that followed the requirement of greater effort in training, the preference was not statistically reliable, even though the trend was in the right direction. The more training that was provided, the greater was the preference for the stimuli that followed the greater response requirement in training. Furthermore, although the preference for the high-effort $\mathrm{S}^{+}$was small (about 56\%), consistent with Clement et al. (2000) there was a larger preference for the high-effort $\mathrm{S}^{-}$(about $65 \%$ ). Thus, although the magnitude of both effects was smaller than that reported by Clement et al., the effects were in the same direction and were proportionally similar.

But why was the magnitude of the within-trial contrast effect found by Arantes and Grace (2008) so small? A possible source of the difference in results could be the nature of the prior experience of the pigeons in the two experiments. The pigeons in the Clement et al. (2000) experiment had had prior experience with a discrete-trial conditional discrimination (matching to sample), whereas the Arantes and Grace pigeons had had extensive experience with concurrent chains, concurrent schedules, and multiple schedules - mostly with variable-interval component schedules in which the pigeons might make 1,000-2,000 responses per hour (J. Arantes, personal communication, August 7, 2007). Thus, these pigeons had a history of pecking on lean schedules of reinforcement, whereas those of Clement et al. did not.

We have recently become interested in the effect of prior schedule history on the within-trial contrast effect. To study prior history, we have given pigeons extensive training with one of the fixed-ratio (FR) schedules that they would later be experiencing during discrimination training. Some pigeons experience a rich schedule, with only a single peck required for reinforcement, whereas others experience a leaner schedule, with 30 pecks required for reinforcement. All pigeons then receive discrimination training as did Clement et al.'s (2000) pigeons. Although the experiment is not complete, we are seeing a within-trial contrast effect in the group pretrained with the rich schedule, but not for the one pretrained with the lean schedule. If pigeons have had extensive experience with relatively lean schedules of reinforcement, the introduction of the FR20 initial link may not be sufficiently aversive to produce the contrast presumed to be responsible for the appearance of the within-trial contrast effect.

Another factor that may have contributed to the failure of Arantes and Grace (2008) to observe a preference for the $\mathrm{S}^{+}$stimulus that followed the FR20 initial link is their use of a fixed-interval 6-sec terminal link following a response to the $\mathrm{S}^{+}$stimulus. Although Clement et al. (2000) used such a terminal-link schedule and found the contrast effect, our more recent research has used a single peck to the $\mathrm{S}^{+}\left(\right.$or S $\left.^{-}\right)$on choice trials (DiGian et al., 2004; Friedrich et al., 2005; Friedrich \& Zentall, 2004; Singer et al., 2007; Singer \& Zentall, 2007), and the closer temporal proximity of the relatively aversive event to the reinforcer as a result of the single-peck requirement may have resulted in a more reliable contrast effect in the more recent research.

Arantes and Grace (2008) also found a larger contrast effect when testing with the two $\mathrm{S}^{-}$stimuli than with the two $\mathrm{S}^{+}$stimuli, a result also reported by Clement et al. (2000). Both Arantes and Grace (2008) and Vasconcelos et al. (2007) attributed that effect to learning to avoid the 
$\mathrm{S}^{-}$. That is, rather than learning to approach the $\mathrm{S}^{+}$, the pigeons were presumed to have learned to avoid the $\mathrm{S}^{-}$. We prefer to view the larger effect on $\mathrm{S}^{-}$preference than on $\mathrm{S}^{+}$preference as a performance effect. When pigeons are given a choice between two $\mathrm{S}^{+}$stimuli, both of which were correct in training, they tend to respond with short latencies and less discriminatively. However, when they are given a choice between two $\mathrm{S}^{-}$stimuli, both of which were incorrect in training, they tend to respond with longer latencies (in psychophysical terms, one might say they have a more conservative criterion for choice or that they choose more "carefully").

The only statistically significant finding reported by Arantes and Grace (2008) is a significant effect of the initial event on test trials (i.e., of whether the test trial began with 20 pecks, 1 peck, or no initial event). We have rarely found that the initial event affects choice of the $\mathrm{S}^{+}$or $\mathrm{S}^{-}$on test trials, but when it has, we have found that it acts as an occasion setter (see DiGian et al., 2004). That is, pigeons tend to choose the discriminative stimulus signaled by the initial event from training. Arantes and Grace, on the other hand, found that their pigeons preferred the $\mathrm{S}^{+}$and $\mathrm{S}^{-}$that in training were signaled by the other initial event. Why they found the opposite effect is not clear, and although such effects can be considered orthogonal to the withintrial contrast effect, they do tend to constrain the potential magnitude of this effect by introducing bias that could potentially limit the magnitude of the within-trial contrast.

Finally, in the present issue, Vasconcelos and Urcuioli (2008) report an effect quite consistent with the withintrial contrast effect. If one considers being on a foodrestricted diet as an aversive state, in comparison with being relatively sated, discriminative stimuli experienced while food-deprived should be preferred over those experienced while sated. This effect was first reported in starlings by Marsh, Schuck-Paim, and Kacelnik (2004) and then replicated by Pompilio and Kacelnik (2005). Recently, the effect has been replicated in grasshoppers (Pompilio, Kacelnik, \& Behmer, 2006). Thus, it appears to have some generality. The major difference in the procedure used by Clement et al. (2000) and the one used by Kacelnik and his collaborators with starlings was that, in Kacelnik's research, training trials involved a single $\mathrm{S}^{+}$ associated with each level of food deprivation, rather than a simultaneous discrimination.

This difference would be of little note, except that Clement et al. (2000) reported that when pigeons were trained with this procedure and were presented on test trials with a choice between the two $\mathrm{S}^{+}$stimuli, no preference was found. Clement et al. explained that in the absence of training to choose between stimuli, their pigeons appeared to peck the first stimulus they saw, and that training them with simultaneous discriminations discouraged them from choosing "impulsively" on test trials. Marsh et al. (2004) and Pompilio and Kacelnik (2005) may have found the contrast effect using a single $\mathrm{S}^{+}$on each trial because their starlings had to fly to the back of a large cage to get the $\mathrm{S}^{+}$to appear. Thus, the discriminative stimulus appeared when the starlings were relatively far away, which prevented them from responding impulsively.
Vasconcelos and Urcuioli (2008) attempted to replicate with pigeons the effect of food deprivation reported by Marsh et al. (2004) and to determine whether the effect could be found using a simultaneous discrimination. Curiously, they were able to replicate the effect using a single $\mathrm{S}^{+}$but not a simultaneous discrimination. This result is puzzling, because their pigeons stood in front of the response panel, as did the pigeons in our experiments. Thus, why their results would be the opposite of ours is not clear.

However, a closer look at their results may resolve some of the mystery. First, the negative results reported by Vasconcelos and Urcuioli (2008) look very similar to the positive results reported by Kacelnik and Marsh (2002). Kacelnik and Marsh found that 10 out of 12 of their starlings (or 83\%) showed a within-trial contrast effect. Similarly, 5 out of 6 (or the same 83\%) of Vasconcelos and Urcuioli's pigeons showed the effect (if the two test sessions are combined, as one can argue they should be), but in the latter case the effect was not statistically reliable. Thus, it is possible that the failure of Vasconcelos and Urcuioli to find a significant effect in their study with a simultaneous discrimination may result from a lack of sufficient power.

Second, to accept that the results of the experiment with the simultaneous discriminations were different from those of the experiment with the single $\mathrm{S}^{+}$, one should be able to show that the two results were statistically different. In fact, on the basis of the data that they report, a $t$ test performed on the difference between the two effects failed to show that the results of the two experiments were significantly different. Thus, the conclusion that the results of the two experiments were different may not be warranted.

Finally, as noted earlier, the within-trial contrast effect may require a considerable amount of overtraining on the original task to establish an adequate association between the manipulation (i.e., the level of deprivation) and the discriminative stimuli. Although Vasconcelos and Urcuioli (2008) found the effect in the experiment involving a successive discrimination with only 12 twenty-trial sessions, typically it takes many more sessions of training for the effect to appear reliably, so the failure to observe the effect under these conditions is not unexpected.

\section{Conclusions}

The several reports of a failure to find a within-trial contrast effect may allow us to explore the possible boundary conditions of this contrast effect. The Vasconcelos et al. (2007) study, together with some of our own research (Friedrich \& Zentall, 2004; Singer et al., 2007; Singer \& Zentall, 2007), suggests that the association between a prior effort and an $\mathrm{S}^{+}$that follows may develop quite slowly and may take $30-50$ overtraining sessions to establish its full strength. The Arantes and Grace (2008) study, together with the results of a study we are currently conducting, suggests that prior experience with lean schedules of reinforcement may weaken the withintrial contrast effect by limiting the relative aversiveness of the high-effort FR20 schedule. And the failure to find a 
within-trial contrast effect with the manipulation of level of food deprivation when an $\mathrm{S}^{+}$appeared simultaneously with an $\mathrm{S}^{-}$(Vasconcelos \& Urcuioli, 2008) may have resulted from a lack of statistical power. When all of the results are taken together, the within-trial contrast effect appears to be a reliable phenomenon that can be found using a variety of prior relatively aversive events, including effort (number of pecks; Clement et al., 2000), delay (DiGian et al., 2004), and the absence of food (when food is presented on other trials; Friedrich et al., 2005). It has been shown primarily with a preference for the conditioned reinforcer that precedes reinforcement, but it also has been found in a shift in preference for the location of food (Friedrich \& Zentall, 2004). Furthermore, although most of the research has been done with pigeons, a similar effect has been reported in starlings (Kacelnik \& Marsh, 2002; Marsh et al., 2004; Pompilio \& Kacelnik, 2005), grasshoppers (Pompilio et al., 2006), and humans (both adults [Klein, Bhatt, \& Zentall, 2005] and children [Alessandri, Darcheville, \& Zentall, 2007]).

\section{AUTHOR NOTE}

Preparation of this comment was supported by National Institute of Mental Health Grant MH-59194. I thank Rebecca Singer and Jérôme Alessandri for their comments on an earlier version of this commentary. Correspondence relating to this article may be sent to T. R. Zentall, Department of Psychology, University of Kentucky, Lexington, KY 40506-0044 (e-mail: zentall@uky.edu).

\section{REFERENCES}

Alessandri, J., Darcheville, J.-C., \& Zentall, T. R. (2007). Cognitive dissonance in children: Justification of effort or contrast? Manuscript submitted for publication.

Arantes, J., \& Grace, R. C. (2008). Failure to obtain value enhancement by within-trial contrast in simultaneous and successive discriminations. Learning \& Behavior, 36, 1-11.

Aronson, E., \& Mills, J. (1959). The effect of severity of initiation on liking for a group. Journal of Abnormal \& Social Psychology, 59, 177-181.
Clement, T. S., Feltus, J. R., Kaiser, D. H., \& Zentall, T. R. (2000). "Work ethic" in pigeons: Reward value is directly related to the effort or time required to obtain the reward. Psychonomic Bulletin \& Review, 7, 100-106.

DiGian, K. A., Friedrich, A. M., \& Zentall, T. R. (2004). Discriminative stimuli that follow a delay have added value for pigeons. Psychonomic Bulletin \& Review, 11, 889-895.

Friedrich, A. M., Clement, T. S., \& Zentall, T. R. (2005). Discriminative stimuli that follow the absence of reinforcement are preferred by pigeons over those that follow reinforcement. Learning \& Behavior, 33, 337-342.

Friedrich, A. M., \& Zentall, T. R. (2004). Pigeons shift their preference toward locations of food that take more effort to obtain. Behavioural Processes, 67, 405-415.

Kacelnik, A., \& Marsh, B. (2002). Cost can increase preference in starlings. Animal Behaviour, 63, 245-250.

Klein, E. D., Bhatt, R. S., \& Zentall, T. R. (2005). Contrast and the justification of effort. Psychonomic Bulletin \& Review, 12, 335-339.

Mackintosh, N. J. (1965). Selective attention in animal discrimination learning. Psychological Bulletin, 64, 124-150.

Marsh, B., Schuck-Paim, C., \& KacelniK, A. (2004). Energetic state during learning affects foraging choices in starlings. Behavioral Ecology, 15, 396-399.

Pompilio, L., \& Kacelnik, A. (2005). State-dependent learning and suboptimal choice: When starlings prefer long over short delays to food. Animal Behaviour, 70, 571-578.

Pompilio, L., Kacelnik, A., \& Behmer, S. T. (2006). State-dependent learned valuation drives choice in an invertebrate. Science, 311, 1613-1615.

Singer, R. A., Berry, L. M., \& Zentall, T. R. (2007). Preference for a stimulus that follows a relatively aversive event: Contrast or delay reduction? Journal of the Experimental Analysis of Behavior, 87, $275-285$.

Singer, R. A., \& Zentall, T. R. (2007). Within-trial contrast cannot be attributed to differential delay reduction. Manuscript submitted for publication.

Vasconcelos, M., \& Urcuioli, P. J. (2008). Deprivation level and choice in pigeons: A test of within-trial contrast. Learning \& Behavior, 36, 12-18.

Vasconcelos, M., Urcuioli, P. J., \& Lionello-DeNolf, K. M. (2007). Failure to replicate the "work ethic" effect in pigeons. Journal of the Experimental Analysis of Behavior, 87, 383-399.

(Manuscript received October 8, 2007; revision accepted for publication October 11, 2007.) 